\title{
BISON (Bloodstream Infections and Sepsis Outcomes measurement Network) initiative: an ESGBIS proposal
}

Luigia Scudeller $^{1 *}$, Jesús Rodríguez Bañoº ${ }^{2}$ Winfried V. Kern ${ }^{3}$

From The 4th Meeting of the Core Outcome Measures in Effectiveness Trials (COMET) Initiative Rome, Italy. 19-20 November 2014

\section{Motivation}

Outcome of a bloodstream infection/sepsis (BSI/S) is defined in different ways in different research projects [1]. In this, BSI/S share the characteristics of other fields of medicine; specific issues are related to diversity of causative agents, the clinical focus of infection, severity of comorbid conditions, presence of indwelling devices, multiplicity of affected patient populations, and others [2]. A preliminary list of putative core outcome set (COS) might be:

- mortality

- time-to-clinical stability

- time-to-microbial clearance

- development/resolution of metastatic foci

- adverse events of treatment

- salvage of infected device

- relapse

- compliance

Therefore, the European Society of Clinical Microbiology and Infectious Diseases working group on bloodstream infections and sepsis (ESGBIS) is currently designing a project for the development of a COS in BSI/S.

\section{Objectives}

1. generate a comprehensive long-list of all outcome variables reported in recent randomised controlled studies on BSI/S

2. refine the outcome long-list into a COS agreed by key stakeholders

\footnotetext{
* Correspondence: I.scudeller@smatteo.pv.it

'Clinical Epidemiology and Biostatistics Unit, Scientific Direction, IRCCS Policlinico San Matteo, Pavia, Italy

Full list of author information is available at the end of the article
}

3. define the best measurement methods of proposed COS

4. identify unresolved issues for further research

5. publish the proposed COS in the relevant scientific journals

6. build a COS database with standard fields easily shared across studies

7. monitor uptake of the selected core outcomes in future relevant publications

\section{Methods}

Overall timetable: 2 year from first meeting.

The ESGBIS group is composed by approximately 30 people with different backgrounds (infectious disease, microbiology, intensive care medicine, epidemiology and statistics). We will adopt a combination of methods: two preparatory meetings, restricted and extended Delphi rounds (via email exchanges), semi-structured interviews with patients, systematic review of the literature, final consensus conference (Figure 1).

\section{Expected outputs}

Publication of the systematic review and of the COS in medical journals and development of a standard set of database fields, to be included in eCRF of future studies.

\section{Acknowledgements}

On behalf of the European Society of Clinical Microbiology and Infectious Diseases working group on bloodstream infections and sepsis (ESGBIS)

\section{Authors' details}

${ }^{1}$ Clinical Epidemiology and Biostatistics Unit, Scientific Direction, IRCCS Policlinico San Matteo, Pavia, Italy. ${ }^{2}$ Infectious Diseases, Microbiology and Preventive Medicine, Hospital Universitario Virgen Macarena and Virgen del Rocío, Seville, Spain. ${ }^{3}$ Division of Infectious Diseases, Albert-LudwigsUniversity, Freiburg, Germany. 


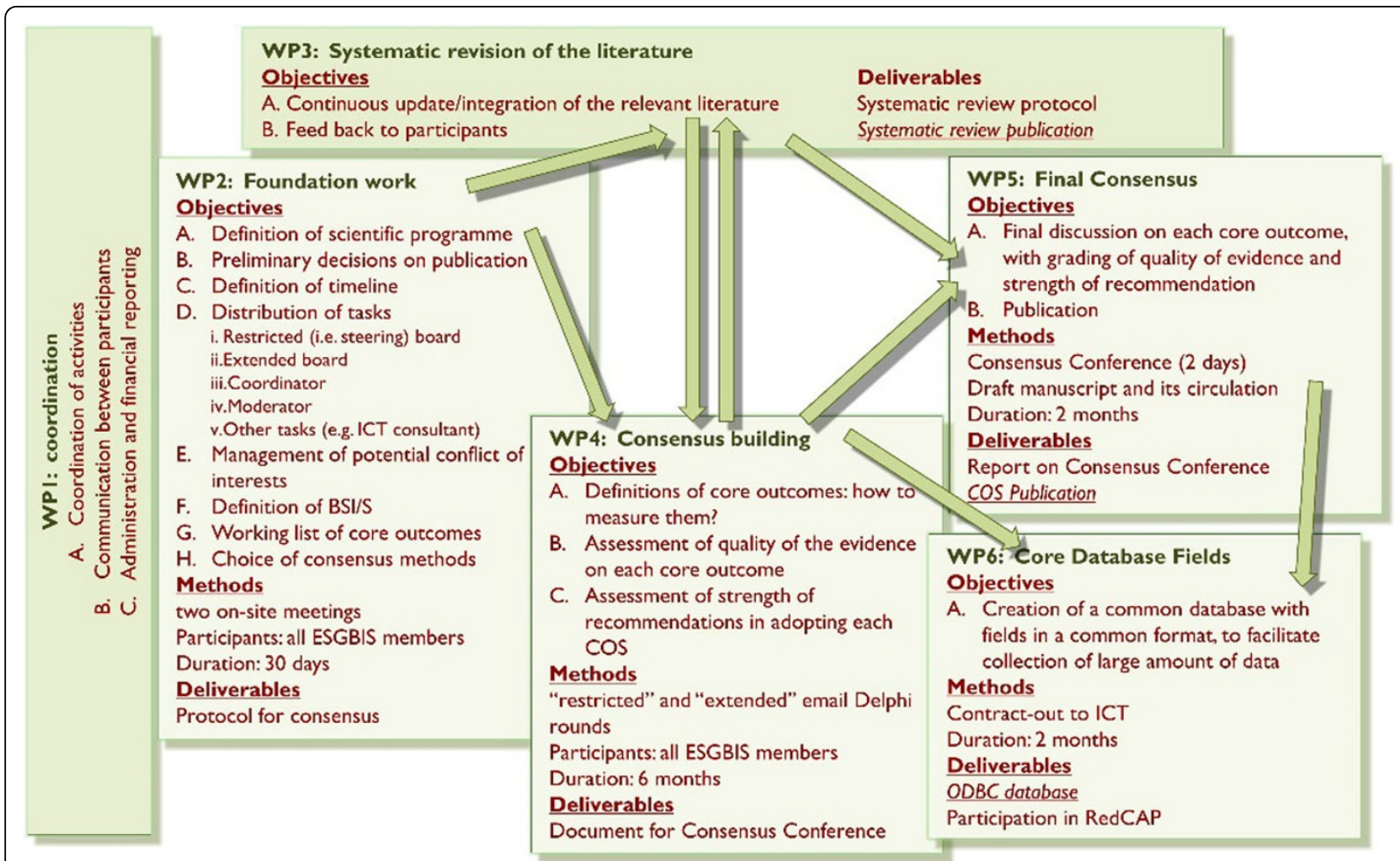

Figure 1 proposed structure of the BISON project

Published: 29 May 2015

\section{References}

1. Marshall JC, Vincent JL, Guyatt G, et al: Outcome measures for clinical research in sepsis: a report of the 2 nd Cambridge Colloquium of the International Sepsis Forum. Crit Care Med 2005, 33(8):1708-16.

2. Bettiol E, Rottier WC, Del Toro MD, Harbarth S, Bonten MJ, RodríquezBaño J, COMBACTE consortium: Improved treatment of multidrugresistant bacterial infections: utility of clinical studies. Future Microbiol 2014, 9:757-71.

doi:10.1186/1745-6215-16-S1-P3

Cite this article as: Scudeller et al: BISON (Bloodstream Infections and Sepsis Outcomes measurement Network) initiative: an ESGBIS proposal. Trials 2015 16(Suppl 1):P3

\section{Submit your next manuscript to BioMed Central and take full advantage of:}

- Convenient online submission

- Thorough peer review

- No space constraints or color figure charges

- Immediate publication on acceptance

- Inclusion in PubMed, CAS, Scopus and Google Scholar

- Research which is freely available for redistribution 